\title{
A Critique of the Mid-Range Energy Forecasting, System Oil and Gas Supply Models
}

W. P. Patton

October 1980

Prepared for the U.S. Department of Energy under Contract DE-AC06-76RLO 1830

Pacific Northwest Laboratory Operated for the U.S. Department of Energy

by Battelle Memorial Institute

W. P. Patton \\ sBattelle}




\section{NOTICE}

This report was prepared as an account of work sponsored by the United States Government. Neither the United States nor the Department of Energy, nor any of their employees, nor any of their contractors, subcontractors, or their employees, makes any warranty, express or implied, or assumes any legal liability or responsibifity for the accuracy, completeness or usefulness of any information, apparatus, product or process disclosed, or represents that its use would not infringe privately owned rights.

The views, opinions and conclusions contained in this report are those of the contractor and do not necessarily represent those of the United States Government or the United States Department of Energy.

PACIFIC NORTHWEST LABORATORY

operated by

BATIELLE

for the

UNITED STATES DEPARTMENT OF ENERGY

Under Contract EY-76-C-06-1830

Printed in the United States of America

Available from

National Technical information Service

United States Department of Commerce

5285 Port Royal Road

Springfield, Virginia 22151

Price: Printed Copy s__ : Microfiche $\$ 33,00$

NTIS

*Pages Selling Price

001-025 $\quad 54.00$

026-050 $\quad \$ 450$

$051-075 \quad \$ 5.25$

$076-100 \quad 56.00$

$107-125 \quad 56.50$

$126-150 \quad 57.25$

$151-175 \quad \$ 8.00$

$176-200 \quad 59.00$

201-225 $\quad 59.25$

$226-250 \quad 39.50$

$251.275 \quad 510.75$

$276.300 \quad \$ 11.00$ 


\section{3}

A CRITIQUE OF THE MID-RANGE ENERGY FORECASTING, SYSTEM OIL AND GAS SUPPLY MODELS

W.P. Patton

October 1980

Prepared for

the U.S. Department of Energy

under Contract DE-AC06-76RLO 1830

Pacific Northwest Laboratory

Richland, WA 99352 


\section{ACKNOWLEDGMENTS}

I would like to acknowledge the patient and thoughtful suggestions, comments and criticisms of Leslie Nieves, Mac Callaway, Alan Rockwood and Jack Tawil at Pacific Northwest Laboratory. I am particularly indebted to Vijay Mather at Cleveland State University for his thorough, perceptive critique of this paper. Any errors and omissions are, of course, my own. 
.

,

. 


\section{SUMMARY}

This paper examines the Mid-Range Energy Forecasting System (MEFS) oil and gas supply models on the basis of how well their structures and assumptions conform to accepted economic principles. The paper first discusses the structure of the MEFS oil and gas supply models, then analyzes weaknesses of those models, and finally suggests changes in the models to improve their performance.

The MEFS oil and gas models are found to be weak, on theoretical grounds, in several respects. First, because drilling effort is estimated using average rather the marginal production costs, supply projections are high and price projections are low. That estimation method also invalidates the normal assumption that the equilibrium solutions of the MEFS oil and gas models maximize consumers' plus producers' surpluses. Second, drilling effort is allocated over time on the basis of rig availability. Rig capacity is added according to an inflexible schedule that is unaffected by economic variables such as prices and interest rates. The result of the inflexible rig investment schedule is that capacity tends to build up faster than reserves are depleted, so oil and gas production tends to increase over time at each price level, in spite of the fact that both average and marginal production costs are increasing as reserves are depleted. Third, because the rate of oil and gas extraction from reserves is invariant to petroleum prices, there is no wellhead production response to price changes. Finally, because MEFS oil and gas "supply curves" mix long-run and short-run concepts they are not consistant in their implied behavior. Each point on MEFS oil and gas "supply curve" represents the maximum amount of production that is possible, given available rig capacity. By linearly interpolating production response among nine discrete short-run supply points, the MEFS oil and gas "supply curves" implicitly assume that rig capacity can be instantly expanded or contracted in the short-run. This violates the definition of the short-run as a time period in which the level of at least one factor of production is fixed. 


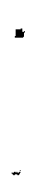


CONTENTS

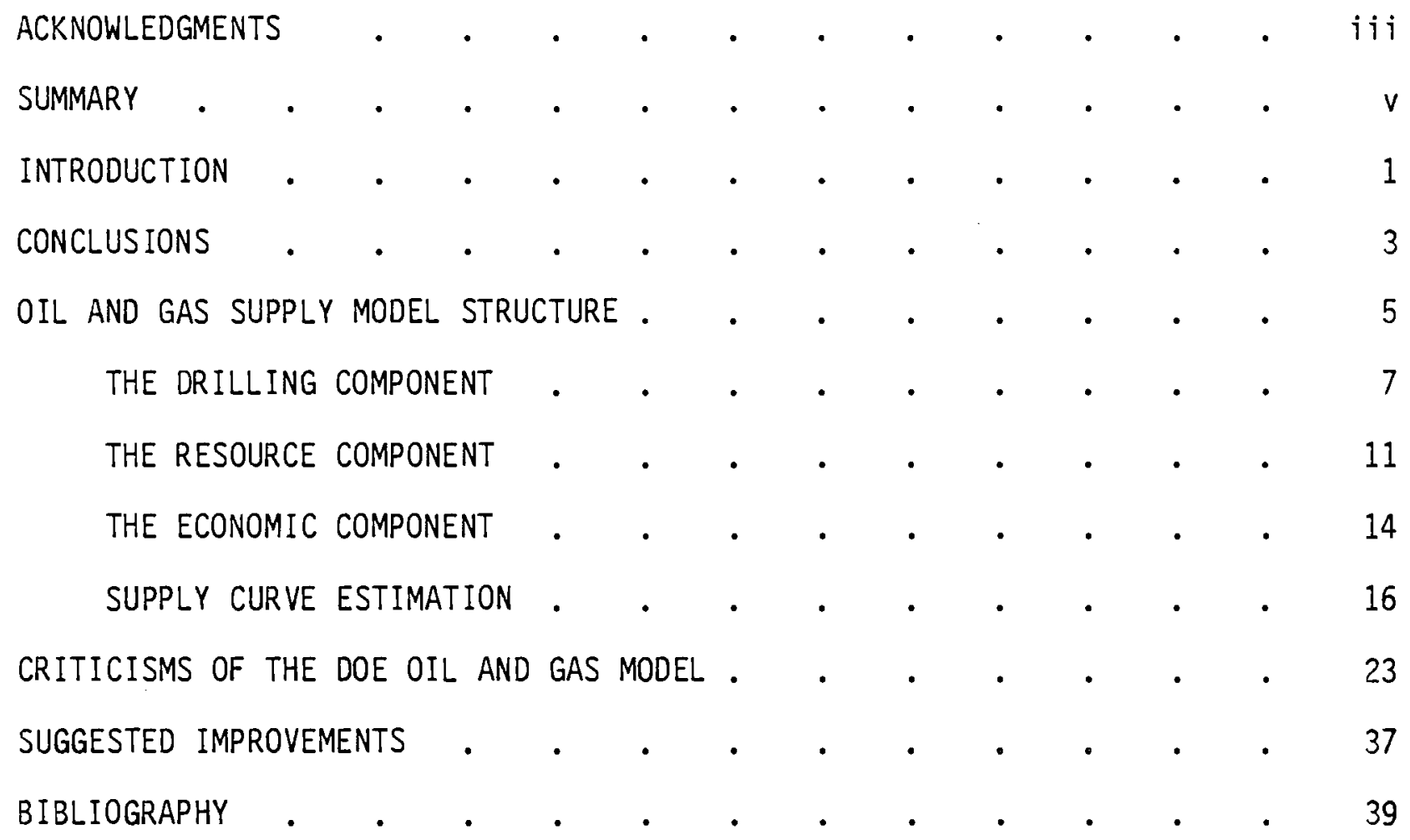

vii 
- 


\section{FIGURES}

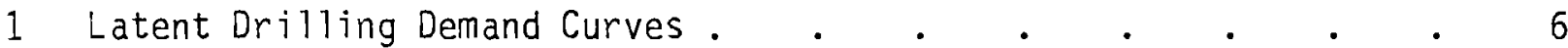

2 Price and Drilling Trajectories . . . . . . . . . 8

3 Generation of Latent Drilling Demand . . . . . . . . 15

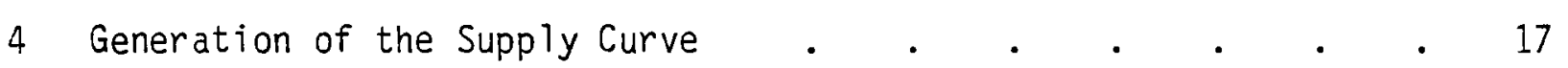

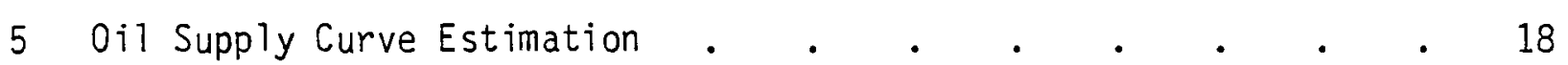

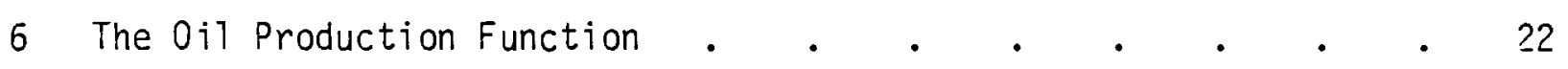

Latent Drilling Demand Based on Profit Maximizing
Behavior . . . . . . . . . . 26

8 Latent Drilling Demand for Average and Marginal

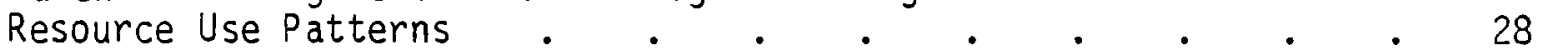

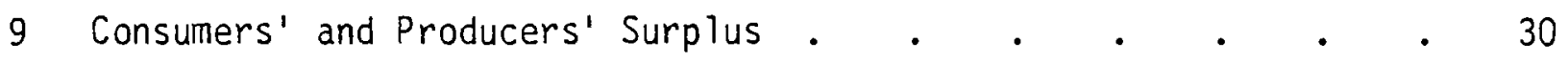





\section{INTRODUCTION}

The Mid-Range Energy Forecasting System (MEFS) is a model used by the Department of Energy to forecast domestic production, consumption and price for conventional energy sources on a regional basis over a period of 5 to 15 years. Among the energy sources included in the model are oil, gas and other petroleum fuels, coal, uranium, and electricity. Final consumption of alternative energy sources is broken into end-use categories, such as residential, commercial and industrial uses. Regional prices for all energy sources are calculated by iteratively equating domestic supply and demand.

The purpose of this paper is to assess the ability of the $0 i 1$ and Gas Supply Submodels of MEFS to reliably and accurately project oil and gas supply curves, which are used in the integrating model, along with fuel demand curves to estimate market price. The reliability and accuracy of the oil and gas model cannot be judged by comparing its predictions against actual observations because those observations have not yet occurred. The reliability and reasonableness of the oil and gas supply model can be judged, however, by analyzing how well its assumptions and predictions correspond to accepted economic principles. This is the approach taken in this critique.

The remainder of this paper describes the general structure of the oil and gas supply model and how it functions to project the quantity of oil and gas forthcoming at given prices in a particular year, then discusses the economic soundness of the model, and finally suggests model changes to improve its performance. 


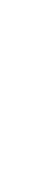




\section{CONCLUSIONS}

The DOE oil and gas supply model appears to be weak on theoretical grounds, both in calculating the level of drilling effort that would be forthcoming at different prices, and in determining the level and timing of investment and production. Because of these weaknesses, we feel that price projections based on equilibrium among "supply curves" generated by the DOE oil and gas model and econometric demand curves, are likely to be inaccurate. 
. 


\section{OIL AND GAS SUPPLY MODEL STRUCTURE}

The oil and gas supply models, which are used in the Mid-Range Energy Forecasting System, have evolved over time. These models were originally developed by the National Petroleum Council (NPC) as engineering simulation models of $0 i 1$ and gas production. In their original form, the models projected $0 i 1$ and gas production based on historical drilling patterns, discovery rates, recovery factors, and decline rates. The NPC $0 i 1$ and gas production models were based on engineering relationships and operated completely independently of petroleum prices.

Around 1972, the NPC supply model was acquired and modified by the Federal Energy Administration (FEA), now an agency within the Department of Energy (DOE). The FEA model of $0 i 1$ and gas production was modified to make $0 i 1$ and gas production estimates responsive to petroleum prices. The basic mechanism through which supply responded to price was in the level of drilling activity. Even though the FEA model included a supply response to price, it was limited in its analytical capabilities in two respects. First, the model could only project supply response to a price projected at a fixed level into the future. Even if price was expected to increase or decline over time, the model was incapable of varying production response. Second, even though natural gas and other petroleum coproducts were discovered in association with oil, the level of drilling effort in the oil model was unaffected by the prices of natural gas and other coproducts.

Under the auspices of DOE, improvements in the economic assumptions of the model have continued. The DOE models of $0 i 1$ and gas supply have been modified to handle supply projections for nonconstant price trajectories. Furthermore, recent versions of the DOE model have been modified so that oil and gas supplies are responsive not only to their own price, but to the prices of jointly produced co-products. These improvements remove two of the limitations inherent in the FEA version of the model. Nevertheless, the DOE model still has some limitations that may adversely affect its performance. These limitations are discussed in later portions of this paper. 
The structures of the DOE Oil and gas submodels are virtually identical with two slight exceptions. First, gas finding rates are a function of both exploratory and developmental drilling, while oil finding rates are a function of exploratory drilling. Second, the gas model does not include components to represent enhanced production methods such as secondary and tertiary recovery processes. Natural gas reserves are added from two sources of drilling. Associated natural gas is discovered in the process of drilling for oil, while nonassociated natural gas is discovered independent of 011 deposits. In the DOE gas supply model, associated natural gas reserves are calculated in the oil supply model and added to nonassociated gas, which is calculated in the natural gas drilling submodel. 0 il reserves, on the other hand, are calculated only in the oil drilling submodel.

The oil and gas submodels are so similar that a separate discussion of each would be inefficient. Thus, unless otherwise stated, throughout the remainder of this paper the functioning of the oil submodel shall be discussed with the understanding that the gas submodel works the same way, with the exception of the differences enumerated in the preceding paragraph.

Currently, the DOE oil submodel consists of three distinct components: 1) drilling, 2) resources, and 3) economic. These three components interact with each other to determine the quantity of oil and associated natural gas produced.

The drilling component allocates the cumulative amount of profitable drilling footage among different production regions over time, given expected prices and constraints on the amount of footage from new and existing rigs available for exploratory drilling in any particular year.

The resource component converts the annual amount of footage drilled in each region into regional proved reserve additions of oil, classifies those reserves into oil that may be produced using primary, secondary or tertiary techniques, and estimates the annual regional quantity of $0 i 1$ produced based on the rate at which oil is extracted from proven reserves.

The economic component calculates minimium acceptable prices, which are necessary to cover the costs of different levels of exploration, development and production. 
The following sections of this paper discuss how the drilling, resource and economic components work, and how those components interact to determine a supply curve. Although each individual component is relatively well documented in publications we have reviewed, the exact way in which the components work together to compute a supply curve is extremely poorly documented. We were forced to review several different documents to grasp how components of the model are interrelated. To further complicate matters, some of the documentation on the oil supply model appears to be contradictory. Thus, the comments below regarding how the components of the oil supply model are linked together to project supply curves represent our best understanding of how the model works.

THE DRILLING COMPONENT

The drilling component serves two purposes in the DOE supply model. First, it uses regional latent drilling demand curves to calculate total cumulative footage that could profitably be drilled in each region, at a given price. Second, based on the availability of drilling rigs, it allocates cumulative regional drilling footage over time. That allocation forms a drilling trajectory, which represents the amount of regional exporatory footage drilled each year. This annual regional exploratory footage is then used in the resource component to calculate annual quantities of oil that would be produced, given that trajectory of drilling effort over time.

Latent drilling demand curves, which are estimated for each domestic production region, represent the cumulative amount of footage that can profitably be drilled at different prices. To calculate latent drilling demand curves, the supply model is run for an ambitious drilling program. Projected drilling activity is run through the resource component to estimate the quantities of oil and associated natural gas that would be produced over time. The production schedule is then fed into the economic component to estimate the minimum acceptable price, associated with a given level of production, which must be received to result in a present value of revenues minus expenditures of zero. Minimum acceptable price associated with each level of cumulative footage drilled represents the correspondence between cumulative footage drilled and price. This correspondence defines a latent drilling demand curve. 
Latent drilling demand curves for three hypothetical oil production regions are illustrated in Figure 1 . The shapes of regional latent drilling curves are determined by the discount rate, regional proven reserve decline rates, finding rates, recovery factors and costs of production. The exponential shape of the latent drilling demand curves results from the fact that regional finding rates in the resource component are a function of cumulative regional footage drilled and decrease at an increasing rate as cumulative footage increases.

Once regional latent drilling demand curves are developed, they are used to estimate regional drilling trajectories, which indicate the annual amount of footage drilled in each region. Regional drilling trajectory curves are generated from several assumptions regarding the availability of drilling rigs and rig producing plants. The drilling model assumes that cumulative explora-
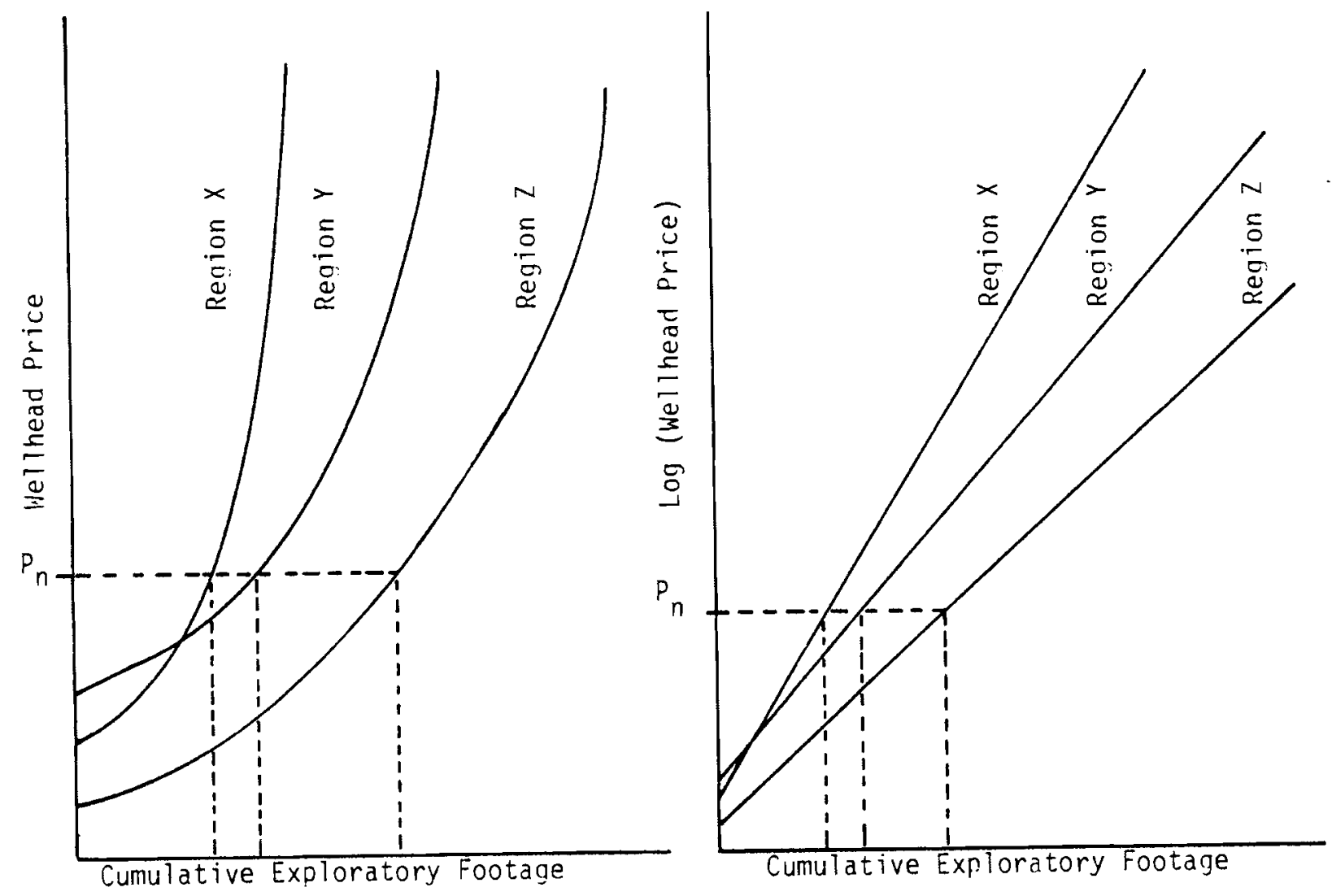

FIGURE 1. Latent Drilling Demand Curves 
tory drilling footage must be allocated from one of three sources: 1) existing rigs, 2) new rigs from existing plants, or 3) new rigs from new plants.

If the total amount of footage available from existing rigs (4.5 times the number of existing rigs, times average feet drilled/rig) is insufficient to fulfill cumulative footage demanded at a given price, then new rigs from existing plants are produced. If the footage available from new rigs produced by existing plants is insufficient to satisfy cumulative drilling demand, new plant capacity is added until cumulative demand for drilling footage is completely satisfied. Since new plant capacity is added over a period of several years, there is a $1 \mathrm{ag}$ between the time at which new rig capacity is needed and the time it comes online.

Once the drilling component has calculated the amount of drilling demand that must be satisfied by footage from each source, it calculates the amount of footage drilled each year by estimating the amount of footage available from each source. The amount of footage from existing rigs in each year is equal to the number of rigs available in the preceding period times the average footage per rig, times $9 / 10$ (straight-line depreciation over a 10-year life). The amount of footage available from new rigs from existing plants is equal to the number of $\mathrm{plants}$ existing in the preceding period, times the average number of rigs produced/plant, times $9 / 10$ (straight-line depreciation over 10 year plant-life), times $1 / 2$ (average use of new rigs produced during year). The amount of footage available from new rigs produced in new plants equals $1 / 15$ (new plants are added to capacity at a constant rate over a 15-year planning horizon), times the total number of new plants that must be added to satisfy cumulative footage demanded, times $1 / 2$ (average amount of use from new rigs produced during the year). Summing the total regional footage available from each source in each year, the drilling model determines regional drilling trajectory.

In practice, the drilling component is run in two modes. In the first mode, the drilling component is run to calculate cumulative drilling demand, assuming that real price is constant over a 30-year period. Then a single drilling trajectory curve is calculated for that price, using the rig and plant capacity assumptions discussed above. This process is repeated to generate drilling trajectories for different prices. 
The second mode of operation allows the drilling submodel to generate drilling trajectories for nonconstant prices. Initially, a price sequence is generated. The drilling component is then run to determine cumulative drilling footage demanded at an initial price. The rig availability portion of the drilling component is then run to determine footage from each source of rigs for the initial year. Then, the drilling component is rerun for prices from successive years in the price series, and drilling trajectories are recalculated iteratively to get the amount of footage available over time. The drilling component is rerun for nine different price trajectories in the same iterative fashion to generate a drilling trajectory for each hypothesized price trajectory.

The drilling trajectories generated in the drilling component indicate the amount of footage drilled each year in response to different price trajectories. This information is used in the resource component to generate the amount of production that would be forthcoming in response to different price trajectories. The correspondence between price and drilling trajectories is illustrated in Figure 2.

\section{Constant Price Case}
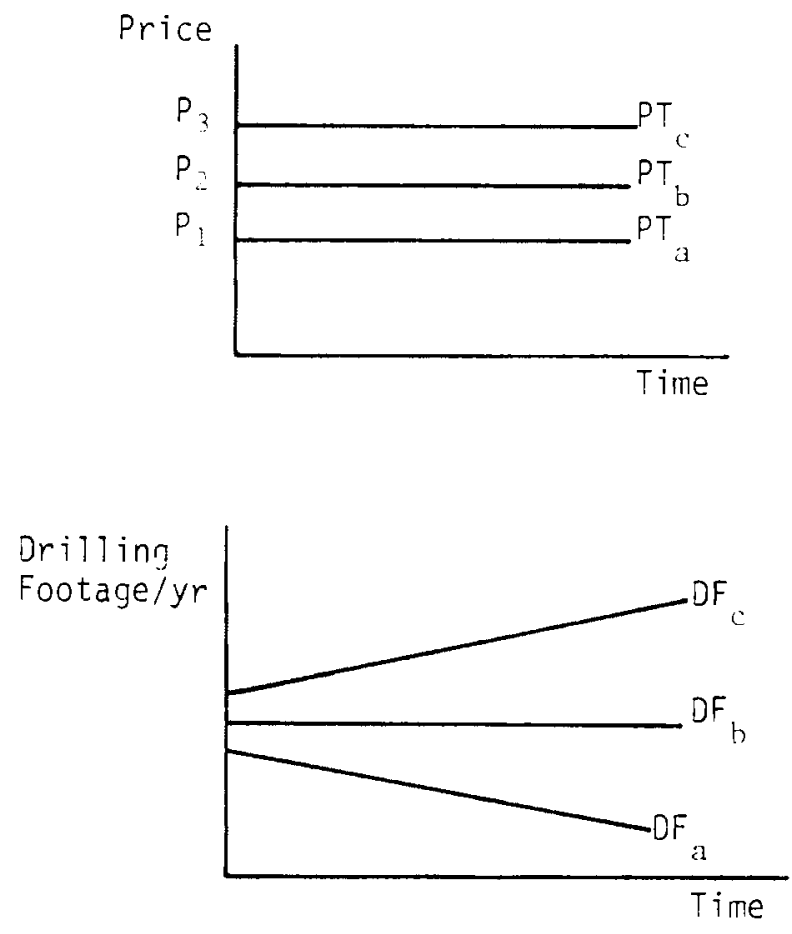

\section{Ramped Price Case}

Price
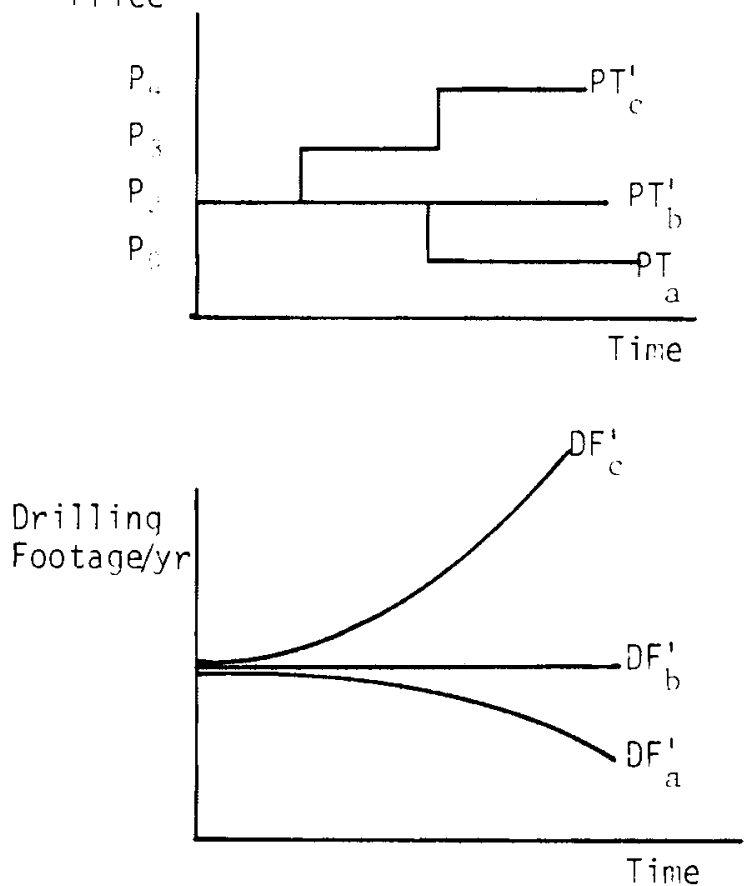

FIGURE 2. Price and Drilling Trajectories 


\section{THE RESOURCE COMPONENT}

The resource component converts drilling activity into production. In the DOE oil supply model, production comes either from old or new fields. The resource component handles old fields slightly differently from new fields, so we shall first discuss how the resource component converts reserves from old fields into production and then how it transforms oil from new fields into production.

Production from old fields in any given year is calculated by multiplying regional reported reserves times a fixed regional decline rate based on historical data. Regional decline rates are the rates at which oil is extracted from reserves and placed into production. Some additional oil is added to regional reported reserves over time to reflect the fact that some growth in oil ultimately recovered from old oil fields occurs as a result of extensions, revisions and new plays. Ultimate recovery from old fields is estimated by applying Hubbert's multipliers to current estimates of proved reserves.

It should be noted that regional production from old fields flows at a fixed rate from regional reported reserves in the initial time period and is totally unaffected by market prices and costs of production. Production from old fields simply declines until those fields are exhausted.

Production from new fields is affected by the intensity of drilling effort. The resources component estimates production from new reserves by transforming drilling activity into oil-in-place, converting oil-in-place into proven reserves, classifying proved reserves into groups of reserves that may be produced using primary, secondary, or tertiary production techniques, and extracting oil from proven reserves to calculate production. $0 i 1$ does not pass instantly from oil-in-place, to proven reserves, into production, but is subject to lags along the way. A one-year lag exists between the time onshore drilling occurs and the time at which production from new reserves commences. For offshore oil, production increases over a period of several years and then begins to decline.

Regional drilling is converted into oil-in-place by multiplying total annual regional drilling footage times a regional finding rate. Regional finding rates are defined as the amount of oil discovered in a region per foot 
drilled. The finding rate for oil from mature onshore regions is determined by taking the first derivative of a regression equation, which relates cumulative oil-in-place discovered to cumulative exploratory drilling and United States Geological Survey estimates of ultimately recoverable resources.

The equation relating cumulative oil-in-place to cumulative drilling is estimated using historical data and has the following form:

$$
\operatorname{COIP}=\underline{Q}\left(1-e^{-\delta \star C M F T}\right)
$$

where

$$
\begin{aligned}
\text { COIP } & =\text { cumulative oil-in-place discovered } \\
Q & =\text { ultimately recoverable resources } \\
\text { CMFT } & =\text { cumulative exploratory drilling footage } \\
\delta & =\text { regional constant }
\end{aligned}
$$

The finding rate is expressed:

$$
F R=\frac{\partial \text { COIP }}{\partial \operatorname{CMFT}}=Q^{* \delta *} e^{-\delta * \text { CMFT }}
$$

The second and third derivatives of COIP, with respect to cumulative drilling, indicate that finding rates for mature onshore regions decrease at an increasing rate.

$$
\begin{aligned}
& \frac{\partial F R}{\partial C M F T}=\frac{\partial^{2} \text { COIP }}{\partial \mathrm{CMFT}^{2}}=-Q^{\star} \delta^{2} \star e^{-\delta \star C M F T}<0 \\
& \frac{\partial^{2} \mathrm{FR}}{\partial \mathrm{CMFT}^{2}}=\frac{\partial^{3} \text { COIP }}{\partial \mathrm{CMFT}^{3}}=Q^{\star} \delta^{3 \star} e^{-\delta \star C M F T}>0
\end{aligned}
$$

For new onshore and offshore regions, sufficient historical data are not available to estimate regression equations for cumulative oil-in-place as a function of cumulative drilling. Consequently, the finding rate for Alaska and offshore regions is approximated by the following equaton.

$$
F R=Y * e^{-(Y / A) * C M F T}
$$


$Y=$ initial finding rate

$A=$ discoverable resources remaining

The first and second derivatives of finding rate with respect to cumulative drilling, indicate that the finding rates for new onshore and offshore regions, like those for mature onshore regions, are decreasing at increasing rates as drilling progresses.

$$
\begin{aligned}
& \frac{\partial F R}{\partial C M F T}=\left(-Y^{2} / A\right) * e^{-(Y / A) * C M F T}<0 \\
& \frac{\partial^{2} F R}{\partial C M F T^{2}}=\left(Y^{3} / A^{2}\right) * e^{-(Y / A) * C M F T}>0
\end{aligned}
$$

Once regional oil-in-place is calculated, it is converted to regional reserves, using regional recovery factors and appropriate time lags. Recovery factors are based on historical data and represent the ratio of reserves to oil-in-place discovered. Recovery factors are broken into primary, secondary, and tertiary categories. The amount of oil-in-place discovered in a given year is lagged to reflect the amount of time necessary to develop reserves, then multiplied times primary, secondary and tertiary recovery factors to get primary, secondary and tertiary reserve additions. These reserve additions are added to existing reserves, and production is estimated according to regional decline rates.

Regional decline rates are the rates at which oil is extracted from regional reserves and converted into production. These decline rates are fixed in the DOE oil and gas supply model and, thus, are invariant to petroleum prices. Annual regional production in a given year is found by multiplying the amount of regional reserves existing in that year times the regional decline rate. The sum of regional production estimates yields national production.

In the exploration and development process for $0 i 1$, other petroleum coproducts, including natural gas, are discovered. The resources component 
for $0 i 1$ estimates the amounts of associated natural gas and other petroleum coproducts, added to reserves as a result of $0 i 1$ exploration.

\section{THE ECONOMIC COMPONENT}

The economic component of the DOE oil and gas supply model calculates the minimum acceptable prices associated with different levels of drilling activity. Minimum acceptable price (MAP) is the price that must be received by oil producers to generate enough discounted revenue to cover the discounted cost of exploration, development and production associated with a given amount of oil.

Calculation of minimum acceptable price in the economic component proceeds from the assumption that all production investments and costs are paid for according to a uniform annual stream of payments. Production from reserves flows at a uniform, continuous rate over time so that discounted revenue from production can be found by multiplying a constant expected price by discounted production (in physical units). MAP analysis further assumes that investment in exploratory drilling will continue until the present value of expected revenues minus the present value of expenses is zero.

The assumption that MAP equates the value of discounted revenue minus discounted costs implies that:

$$
\begin{aligned}
& \operatorname{MAP}_{A} * \tilde{Q}-\tilde{I}-\tilde{K}-\tilde{C}=0 \\
& \tilde{Q}=q_{0}^{*} \int_{0}^{T} e^{-(a+r) t} d t=q_{0}^{*}\left[\frac{1-e^{-(a+r) t}}{a+r}\right] \\
& \tilde{I}=I(C M F T) * \int_{0}^{T} e^{-r t} d t=I(C M F T) *\left[\frac{1-e^{-r T}}{r}\right] \\
& \tilde{K}=k^{*} \int_{0}^{T} e^{-r t} d t=k *\left[\frac{1-e^{-r t}}{r}\right] \quad(k \text { constant }) \\
& \tilde{C}=b q_{0}^{*} \int_{0}^{T} e^{-(a+r) t} d t=b * \tilde{Q}
\end{aligned}
$$


where

$q_{0}=$ initial production rate

$k=$ uniform stream of fixed operating costs

$b=$ cost of production per unit of production

$\mathrm{a}=$ reserve decline rate

$r=$ discount rate

MAP $_{A}=$ minimum acceptable price

$\tilde{Q}=$ discounted quantity of expected production over time, in physical units

$I(C M F T)=$ functional relationship between investment expenditures and cumulative exploratory drilling

$\tilde{I}$ = discounted value of exploratory drilling expenditures, in dollars

$\tilde{K}=$ discounted value of annual fixed operating costs, in dollars

$\tilde{C}=$ discounted value of variable operating costs, in dollars.

Equation (8) can be restated to show that MAP $A$ is the price that equals average discounted cost of production.

$$
\operatorname{MAP}_{A}=\frac{\tilde{I}+\tilde{K}+\tilde{C}}{\tilde{Q}}
$$

where

MAP $_{A}=$ Minimum acceptable price that covers average discounted cost of production.

The role of the economic component in the oil supply model is to generate cumulative drilling demand curves by making a run of the model for different levels of drilling activity. Those different levels are parametrically fed into the resource component to generate the amount of production over time that would be forthcoming from given levels of cumulative drilling footage. The economic model is then run to estimate investment, development, and production costs over time. These costs are discounted and then divided by discounted production to get the MAP $_{A}$ of a given amount of cumulative footage. 
This process is repeated for different levels of cumulative footage to map the relationship between minimum acceptable price and cumulative exploratory dri1ling. This relationship is referred to as the latent drilling demand curve in the drilling component section of this paper.

Once latent drilling demand curves have been generated, the economic submodel is not used again in the oil supply model. On subsequent runs, latent drilling demand curves are used by the drilling submodel to determine cumulative footage demanded at a given price. Cumulative footage demanded is allocated over time according to rig and plant capacity; then annual drilling patterns are fed into the resources component to generate temporal production patterns.

\section{SUPPLY CURVE ESTIMATION}

A supply curve represents the maximum quantities of a product that producers are willing and able to $\mathrm{place}$ on the market at different prices. The DOE $0 i 1$ and gas supply model generates "supply curves" for $0 i 1$ and gas at 5year intervals over a 15-year forecasting horizon. It should be noted, however, that what is referred to as a "supply curve" in the DOE 011 and gas supply model is not really a supply curve in an economic sense because it does not reflect profit maximizing behavior on the part of $0 i 1$ producers. This assertion is explained in the following section of this paper. This section, however, deals with how DOE Oil and gas "supply curves" are generated. Figure 3 represents the steps involved in generating latent drilling demand curves. The maximum footage (Max $\mathrm{ft}$ ) drilled is taken from the highest drilling trajectory.

The first major step in the process is to generate latent drilling demand curves. Drilling footage is parametrically increased and fed into the resources component to generate production at different levels of drilling. Production levels are then fed into the economic component to calculate the minimum acceptable prices required for alternative levels of drilling activity. The relationship between cumulative drilling footage and minimum acceptable price defines the latent drilling demands curves, which are illustrated in Figure 1. 


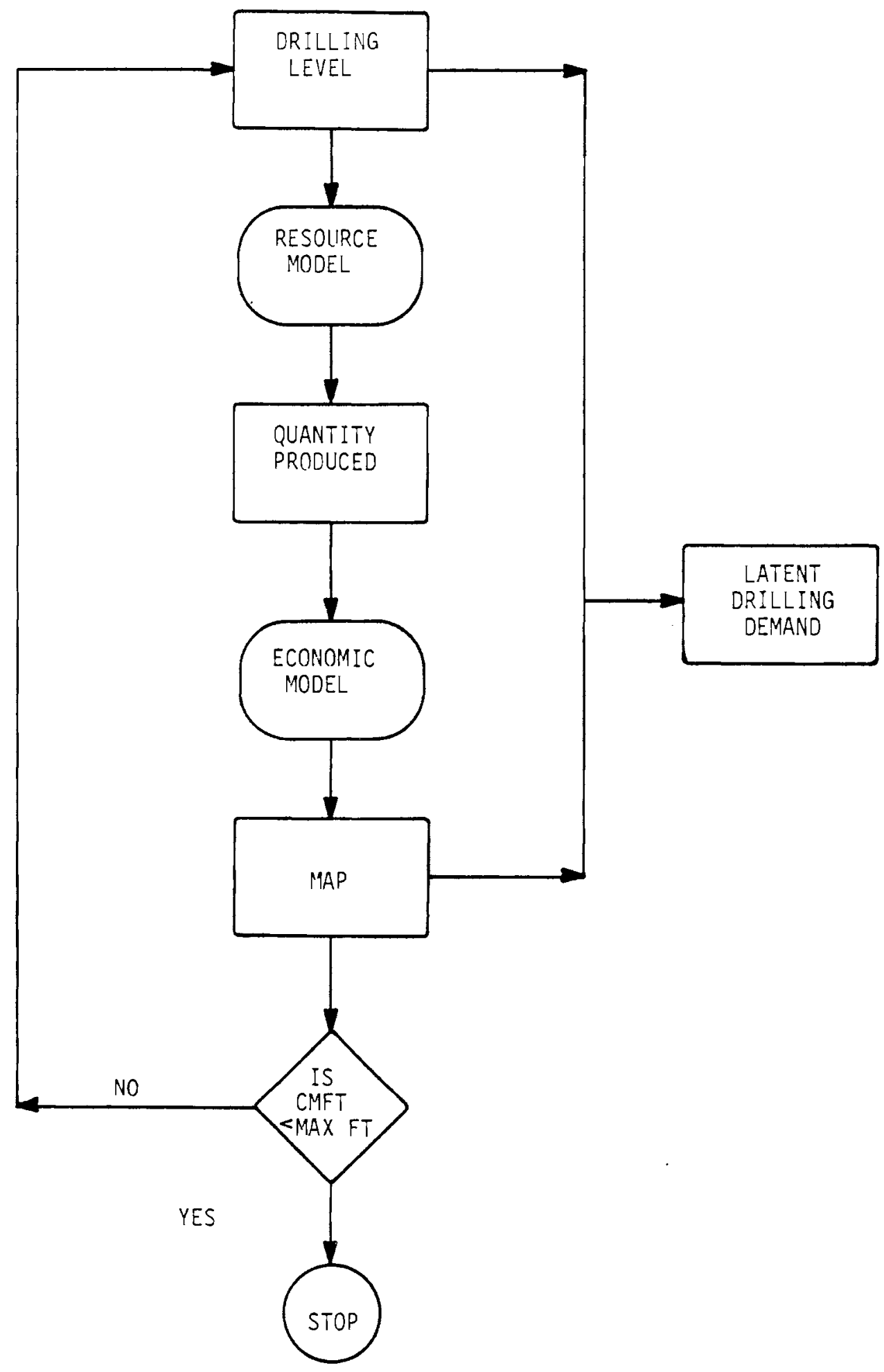

FIGURE 3. Generation of Latent Drilling Demand 
The second major step is depicted in Figure 4. The supply model is run again, using the latent drilling demand curves generated in the initial run to determine the amount of cumulative footage drilled in response to alternative prices. That footage is allocated over time based on rig availability, to determine the drilling trajectory, or the amount of drilling per year.

The annual drilling amount is then fed into the resources submodel to calculate the annual amount of production that will be forthcoming. A "supply curve" for each year is then estimated by associating the amount of production in that year with the MAP ${ }_{A}$ for that level of production. The association between price and production forms a "supply curve".

Figure 5 shows how each point on the "supply curve" is generated. The "supply curves" estimated by the DOE oil and gas models are not really curves, but are actually nine discrete points that are used to approximate a step function. The supply model is run nine times, once for each of nine price trajectories, which may assume constant, increasing, or decreasing prices over time. These nine price trajectories are used to generate nine drilling trajectories, one associated with each price trajectory. The drilling trajectories are fed into the resources submodel to calculate nine trajectories for reserve additions and new production, which correspond to the nine price trajectories. 01d production is independent of price; it simply flows out of old reserves at a constant rate over time. Total production in each year is the sum of old production and new production for that year.

The DOE supply model generates one production trajectory for each of nine price trajectories. To get the annual "supply curve", the amount of production for a given year associated with a given price trajectory is paired with the price for that year on the price trajectory to get a single point on the "supply curve". The remainder of the points on the "supply curve" for a given year is estimated by pairing the prices for that year for each of the price trajectories with the quantities associated with each price. This process is repeated for each year for which "supply curves" are estimated.

It is important to note that the "supply curves" estimated in the DOE oil and gas models shift to the right over time (see Figure 5). This implies that producers would be willing to supply more oil and gas at a given price in 1990 


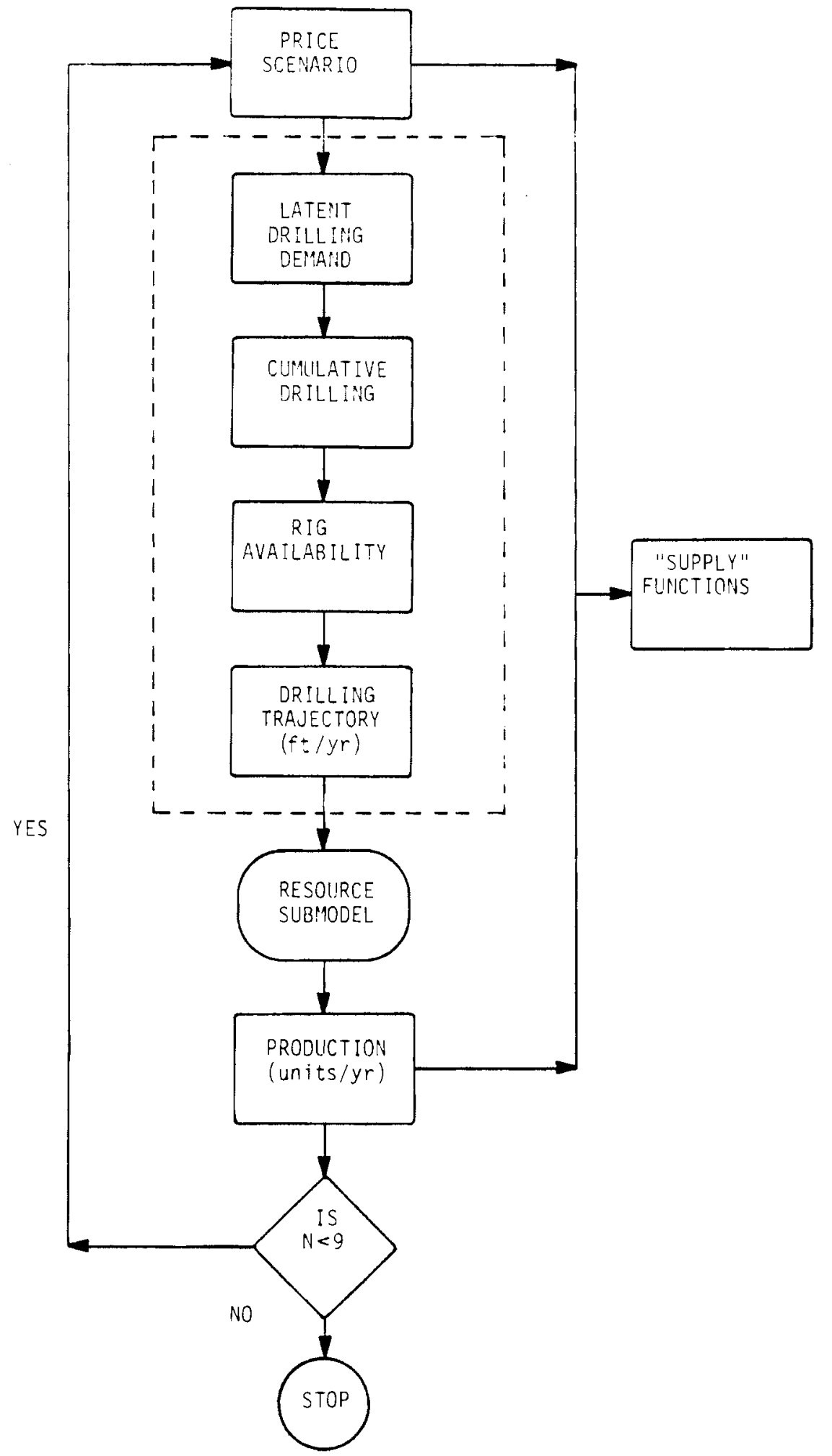

FIGURE 4. Generation of the Supply Curve 


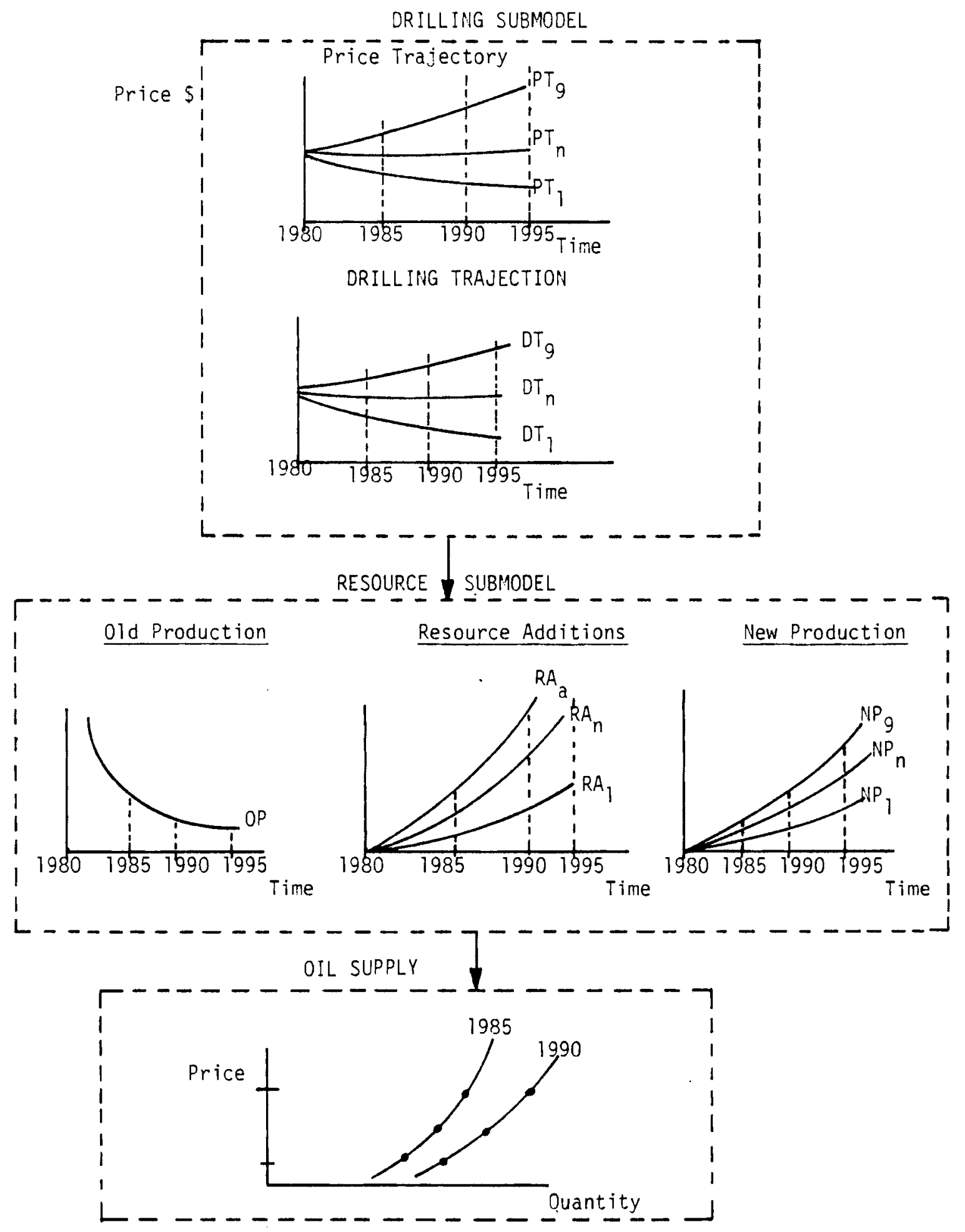

FIGURE 5. 0il Supply Curve Estimation 
than they were willing to supply at the same price in 1985. This rightward shift in "supply curves" over time occurs in spite of the fact that the finding rates for $0 i 1$ and gas are declining as cumulative drilling expands, so that both the average and marginal costs of production are increasing over time. Apparentiy, the rightward shift in the "supply curve" over time is attributable to the fact that drilling in each year is dependent on the number of available rigs and rig producing plants. Over time, rig capacity is added at a faster rate than the rate of decline in the finding rate so that on net, production estimates for a given price tend to rise, despite increasing average and marginal production costs.

The rise in average and marginal production costs as cumulative footage increases $c$ an be demonstrated with reference to the shape of the latent drilling demand curves. Equation (13) showed that minimum acceptable price (MAP $A$ ) is exactly equal to discounted average cost of production. MAP $_{A}$ increases as cumulative footage increases (see Figure 1). Furthermore, cumulative footage is the sum of all footage drilled. Thus, as time passes, more footage is drilled so average costs must also rise. 


\section{CRITICISMS OF THE DOE OIL AND GAS MODEL}

The preceding sections of this paper discussed the way in which the DOE oil and gas model calculates "supply curves" for oil and gas, and alluded to the fact that the "supply curves" generated for oil and gas in the DOE model are not supply curves in the economic sense. In this section of the paper, we will discuss what is implied by an economic supply curve and demonstrate that the DOE "supply curves" do not, in fact, fit the definition. We will then discuss the bias and distortion introduced when predictions of price and quantity are made on the basis of DOE "supply curves" rather than economic supply curves.

An economic supply curve reflects the maximum quantities of a product that profit-maximizing producers are willing to sell at different price levels. The key concept behind the economic supply curve is producers' profit maximizing behavior. One of the basic tenets of economic theory is that profit-maximizing producers only use factors of production to the point at which the value of incremental production from applications of those factors is exactly equal to the incremental cost of applying them.

In the DOE oil and gas supply model, there is one composite factor of production called cumulative drilling footage, which represents a combination of many factors of production, such as labor, land, capital, and management. Presumably, all of these production factors are combined in some way, defined by technology into a composite factor of production called cumulative drilling footage. Although model documentation does not clearly explain how production factors are combined to form drilling footage, they appear to be combined in fixed proportions, which vary depending upon the region. The DOE model also appears to assume, at least when generating latent drilling demand curves, that the supplies of all production factors that go into drilling footage are perfectly elastic at the prevailing market price, so the cost per foot drilled does not change as cumulative footage expands.

The DOE oil and gas supply model, taken as a whole, defines temporal production functions in which a single composite production factor, cumulative footage, is used to produce $0 i 1$ and gas. $0 i 1$ and gas production from these 
engineering production functions increases at a decreasing rate as cumulative footage increases. These engineering production functions determine how much production will be forthcoming from a given level of cumulative footage, but they do not, in themselves, provide information on how much cumulative footage should be drilled to maximize profit.

To show how much cumulative footage must be drilled to maximize profit, given costs of production and product prices, we must first formally derive the structure of the temporal production function from the information provided in DOE model documentation. We derive the mathematical structure of the oil supply model for onshore regions in the equations below, with the understanding that equations for offshore regions can be derived in a similar manner.

From equation (9) we know that discounted production is equal to initial production, times a discounting factor that accounts for the interest rate and the rate of decline in reserves.

$$
\tilde{Q}=q_{0}\left[\frac{1-e^{-(a+r)^{t}}}{a+r}\right]
$$

Furthermore, we know from equation (1) that production from reserves is calculated by multiplying oil-in-place times a recovery factor (RF). If we assume that there are no constraints on the amount of available rigs so that all drilling can be done in the initial period, then the initial amount of production, $q_{0}$, can be found as follows:

$$
q_{0}=Q^{*}\left[\int_{0}^{M A X} e^{-\delta * C M F T} d C M F T\right] * R F
$$

or

$$
q_{0}=Q^{*}\left[1-e^{-\delta * C M F T}\right] * R F
$$

Inserting equation (16) into equation (14), we have derived the equation for discounted output as a function of cumulative footage drilled. Equation (17) is a production function. 


$$
\begin{aligned}
& \tilde{Q}=Q\left(1-e^{-\delta \star C M F T}\right) \star R F \star\left[\frac{1-e^{-(a+r)}}{a+r}\right] \\
& \frac{\partial \tilde{Q}}{\partial C M F T}=\delta \star Q * e^{-\delta \star C M F T} \star R F \star\left[\frac{1-e^{-(a+r)}}{a+r}\right]>0 \\
& \frac{\partial^{2} \tilde{Q}}{\partial C M F T^{2}}=-\delta^{2} Q^{*} e^{-\delta \star C M F T} \star R F \star\left[\frac{1-e^{-(a+r)}}{a+r}\right]<0
\end{aligned}
$$

The properties of the production function are obvious from its first and second derivatives (equations 18 and 19). Production increases at a decreasing rate as cumulative footage and time increase, asymptotically approaching the value $(\underline{Q} * \mathrm{RF}) /(a+r)$. Figure 6 illustrates the shape of the production function implied by the DOE oil supply model.

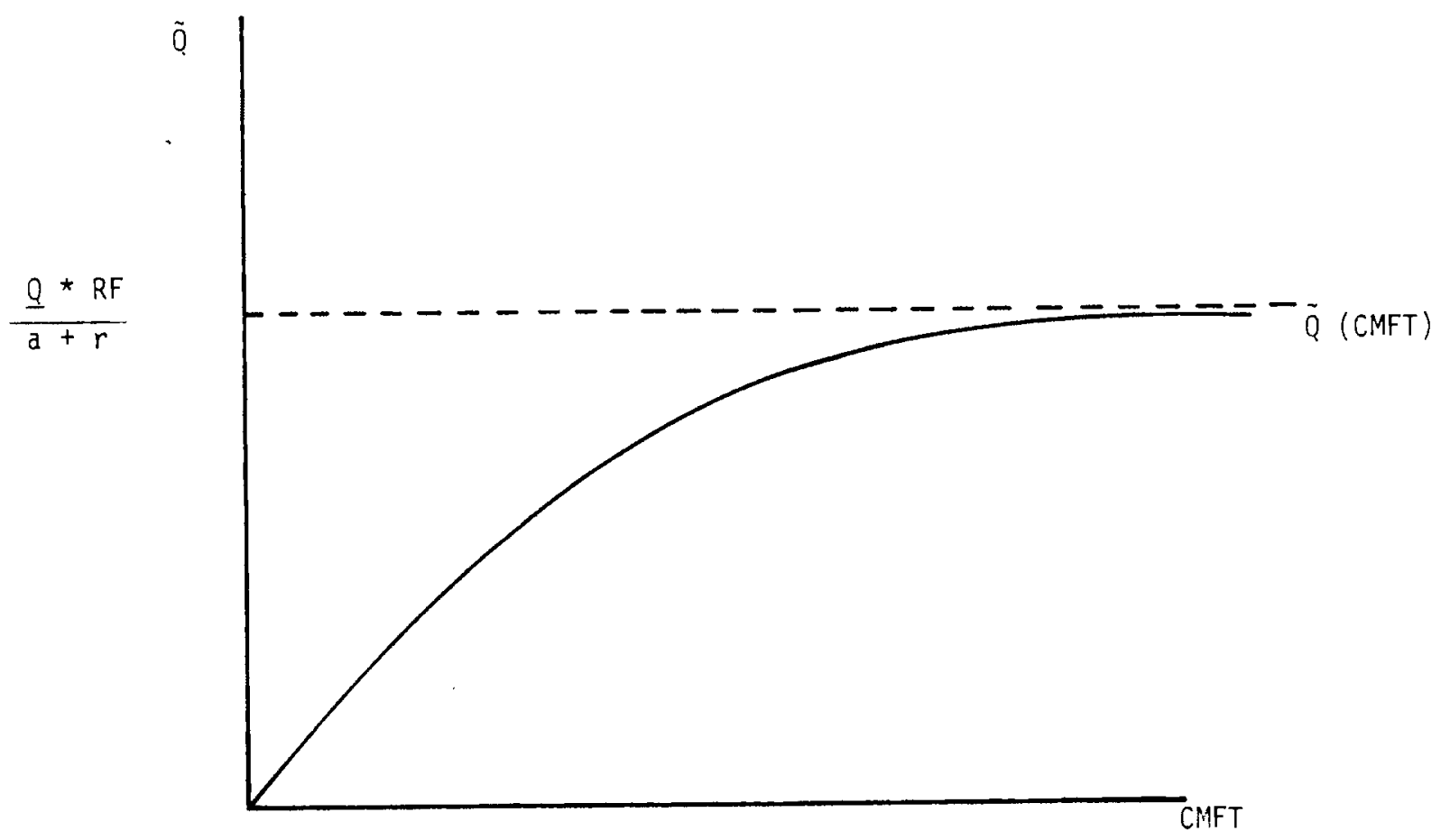

FIGURE 6. The 011 Production Function 
In an intertemporal sense, the objective of profit maximizing producers is to maximize discounted profit $(\tilde{\pi})$, which is equal to discounted total revenue from production, minus discounted total cost. Total revenue is simply price times quantity produced. Total cost is the sum of drilling and operating costs. We shall employ the subscript " $M$ " to indicate that the minimum acceptable price derived from profit maximization is not the same as the minimum acceptable price in the DOE model.

$$
\tilde{\pi}=\operatorname{MAP}_{M} * \tilde{Q}-\tilde{I}-\tilde{K}-\tilde{C}
$$

The first order condition for profit maximization requires that the derivative of profit with respect to cumulative footage be set equal to zero.

$$
\frac{\partial \tilde{\pi}}{\partial C M F T}=\text { MAP }_{M} * \frac{\partial \tilde{Q}}{\partial C M F T}-\frac{\partial \tilde{I}}{\partial C M F T}-\frac{\partial \tilde{K}}{\partial C M F T}-\frac{\partial \tilde{C}}{\partial \tilde{Q}} * \frac{\partial \tilde{Q}}{\partial C M F T}=0
$$

Since $\quad \frac{\partial \tilde{C}}{\partial \tilde{Q}}=b$ and $\frac{\partial K}{\partial C M F T}=0$, equation (21) becomes

$$
\frac{\partial \tilde{\pi}}{\partial C M F T}=\operatorname{MAP}_{M}{ }^{*} \frac{\partial \tilde{Q}}{\partial C M F T}-\frac{\partial \tilde{I}}{\partial C M F T}-b \frac{\partial \tilde{Q}}{\partial C M F T}=0
$$

From equation (22) we see that minimum acceptable price (MAP $M$ ) must be set as follows:

$$
\begin{aligned}
\operatorname{MAP}_{M} & =\frac{\frac{\partial \tilde{I}}{\partial C M F T}+b \frac{\partial \tilde{Q}}{\partial C M F T}}{\frac{\partial Q}{\partial C M F T}} \\
\operatorname{MAP}_{M} & =\left(\frac{\partial \tilde{I}}{\partial C M F T} / \frac{\partial \tilde{Q}}{\partial C M F T}\right)+b
\end{aligned}
$$

The second order condition for profit maximization requires that the second derivative of profit, with respect to cumulative footage, be negative. 


$$
\frac{\partial^{2} \tilde{\pi}}{\partial \mathrm{CMFT}^{2}}=\operatorname{MAP}_{M} * \frac{\partial^{2} \tilde{Q}}{\partial \mathrm{CMFT}^{2}}-\frac{\partial^{2} \tilde{I}}{\partial \mathrm{CMFT}^{2}}-b^{*} \frac{\partial^{2} \tilde{Q}}{\partial C M F T^{2}}<0
$$

or

$$
\frac{\partial^{2} \tilde{\pi}}{\partial \mathrm{CMFT}^{2}}=\frac{\partial^{2} \tilde{Q}}{\partial \mathrm{CMFT}^{2}} *\left(\mathrm{MAP}_{M}-b\right)-\frac{\partial^{2} \tilde{I}}{\partial \mathrm{CMFT}^{2}}<0
$$

We know from equation (19) that $\partial^{2} \tilde{Q} / \partial$ CMFT $^{2}$ is negative. It is unclear from the documentation what, exactly, the relationship is between drilling investment expenditures and cumulative footage drilled. We are certain, from the shape of the latent drilling demand curves that $\partial \tilde{I} / \partial C M F T$ is positive. We suspect that drilling investment expenditures increase at either a constant rate or increasing rate as cumulative drilling footage increases, which implies that $\partial^{2} \tilde{I} / a C_{M F T}{ }^{2}$ is nonnegative. Thus, equation (26) will aiways be negative as long as minimum acceptable price $\left(\right.$ MAP $\left._{M}\right)$ is set higher than average variable operating costs (b).

From equation (24) we know that MAP $_{M}$ minus $b$ equals ( $\left.\tilde{I} / \partial C M F T\right) /(\partial \tilde{Q} / \partial C M F T)$.

$$
\begin{aligned}
& \operatorname{MAP}_{M}-b=\frac{\partial \tilde{I}}{\partial C M F T} / \frac{\partial \tilde{Q}}{\partial C M F T}>0 \\
& \therefore \quad \operatorname{MAP}_{M}>b
\end{aligned}
$$

Therefore, MAP $M$ is always greater than $b$, so that a MAP $_{M}$ equated to the formula in equation (24) insures a profit maximizing use of the composite factor of production (cumulative footage).

The relationship between MAP $_{M}$ and cumulative footage drilled can be found by substituting information from equation (10) and (18) into equation (24) and rearranging terms to get equation (29). 
$\operatorname{MAP}_{M}=\left(\frac{\left[1-e^{-r t]} *[a+r]\right.}{\operatorname{RF} *\left[1-e^{-(a+r) t}\right] r}\right) *\left(\frac{\partial I(\text { CMFT })}{\partial C M F T}\right) *\left(\frac{e^{\delta * C M F T}}{\delta \underline{Q}}\right)+b$

$\operatorname{MAP}_{M}>0$

$$
\begin{aligned}
& \frac{\partial^{\text {MAP }}}{\partial{ }^{M} M}=\delta\left(\text { MAP }_{M}-b\right)>0 \\
& \frac{\partial^{\text {MAP }} M}{\partial C M F T}=\delta^{2} *\left(\text { MAP }_{M}-b\right)>0
\end{aligned}
$$

It is obvious from equations (29) through (32) that: 1) MAP $M$ is always positive for positive values of CMFT, 2) MAP $M$ is an increasing function of CMFT, and 3) MAP $M$ increases at an increasing rate as drilling progresses. The relationship between cumulative drilling and MAP $_{M}$ is illustrated in Figure 7 . The latent drilling demand curve generated by profit maximizing behavior is similar to that generated in the DOE model in terms of shape, but not in terms of intercept and slope.

We can show how much bias is introduced by using the DOE formula rather than the profit maximizing formula to generate latent drilling demand curves by demonstrating the difference between MAP $_{M}$ and MAP $_{A}$ at different levels of cumulative drilling feet. To do this, we must first transform equation (13) into a more appropriate form.

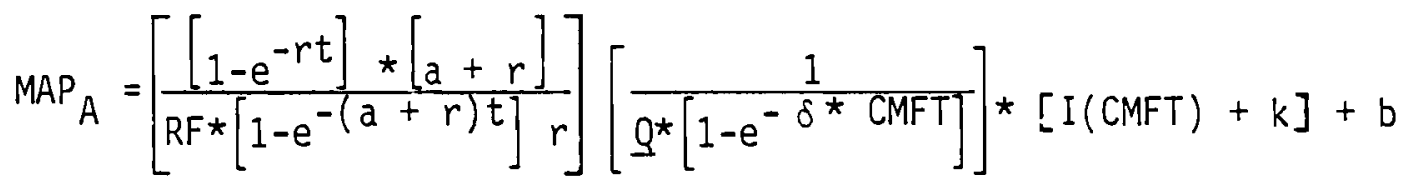

Subtracting equation (29) from equation (33) we get:

$$
\operatorname{MAP}_{M}-\operatorname{MAP}_{A}=K I^{*}\left\{\left[\frac{\partial I(\text { CMFT })}{\partial \mathrm{CMFT}}\right] *\left[\frac{e^{\delta * C M F T}}{\delta}\right]-\left[\frac{I(\mathrm{CMFT})+k}{1-e^{-\delta \star C M F T}}\right]\right\}
$$




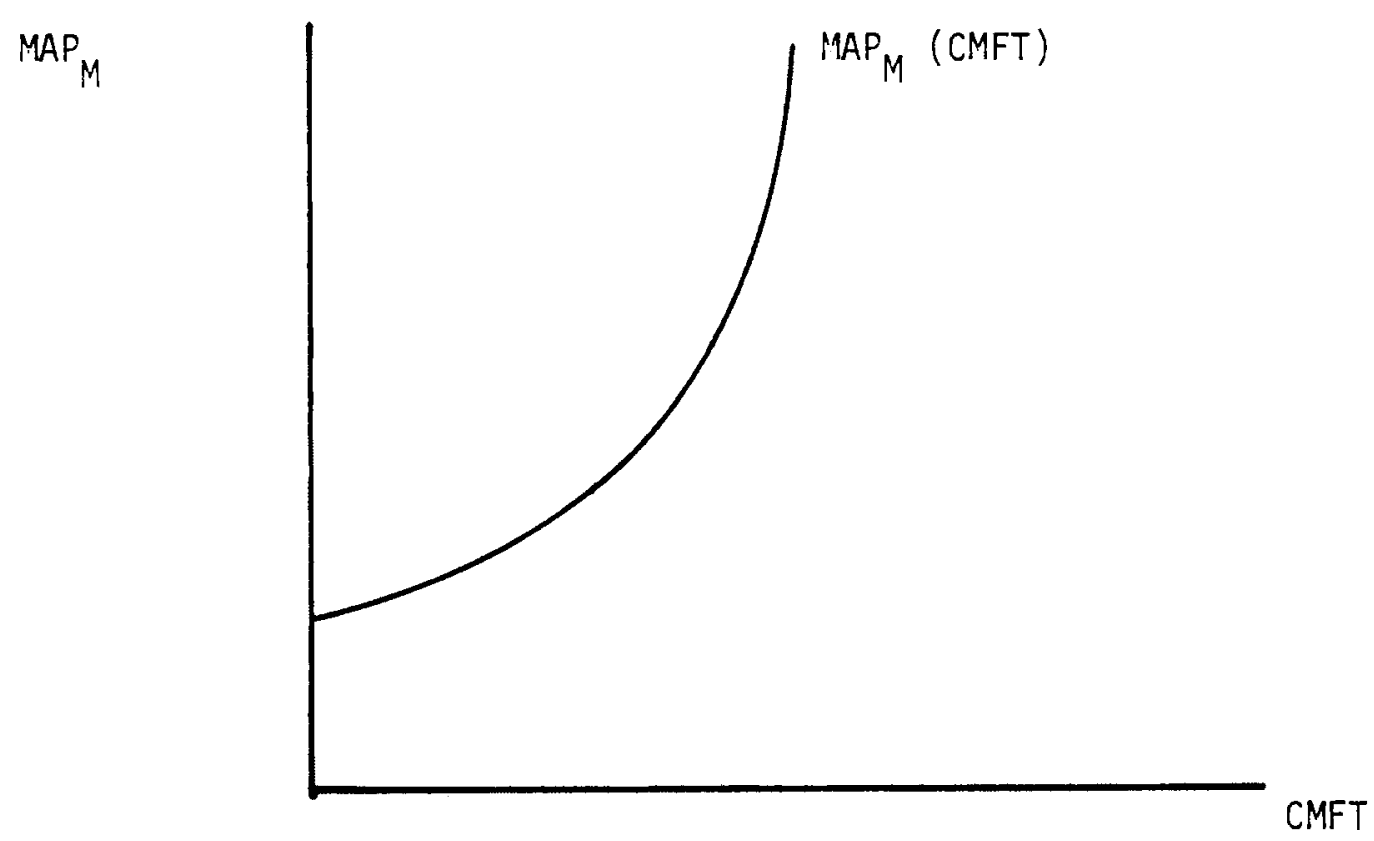

FIGURE 7. Latent Drilling Demand Based on Profit Maximizing Behavior where

$K 1=\left[\frac{\left[1-e^{-r t}\right] *[a+r]}{\operatorname{RF}\left[1-e^{-(a+r) t}\right] r}\right] * 0$

Although the documentation on the oil model is unclear on how drilling investment cost is related to footage drilled, we suspect that they display a linear relationship.

$I($ CMFT $)=Z *$ CMFT

where

$Z=$ average drilling cost per foot $(\$ / f t)$

$\frac{\partial I(\text { CMFT })}{\partial C M F T}=Z$

$\frac{\partial^{2} I(C M F T)}{\partial \text { CMFT }^{2}}=0$ 
Substituting equations (36) and (37) into equation (34) yields:

$M A P_{M}-M A P_{A}=Z \star K 1\left[\left(\frac{e^{\delta \star C M F T}}{\delta}\right)-\left(\frac{C M F T+k / Z}{1-e^{-\delta \star C M F T}}\right)\right]$

which simplifies to:

$\operatorname{MAP}_{M^{-}}-\operatorname{MAR}=\left[\frac{Z \star K 1}{\left[1-e^{-\delta \star C M F T}\right]}\right]\left[e^{\delta \star C M F T}-\delta \star(C M F T+k / Z)-1\right]$

The first term on the right hand side of equation (40) is positive at all nonnegative values of cumulative footage, except zero, at which it is undefined. Consequently, the value of MAP $_{M}$ minus MAP $A$ is negative if $e^{\delta \star C M F T}$ is less than $\delta \star(C M F T+k / Z)+1$. Otherwise, equation $(40)$ is positive.

$\operatorname{MAP}_{M}-$ MAP $_{A}<0$ if $e^{\delta \star C M F T}<\delta \star(C M F T+k / Z)+1$

$\operatorname{MAP}_{M}-$ MAP $_{A} \geq 0$ if $e^{\delta \star C M F T} \geq \delta \star(C M F T+k / Z)+1$

If $k$ (annual fixed operating costs) is equal to zero, MAP $M$ and MAP $_{A}$ have the same intercept and MAP $_{M}$ is greater than MAP $_{A}$ throughout the range of all positive levels of cumulative drilling footage. If $k$ is positive, MAP $M$ is less than MAP $_{A}$ at very low levels of drilling, but as drilling progresses, MAP $_{M}$ eventually becomes 1 arger than MAP $_{A}$. The discrepency between MAP $_{M}$ and MAP $_{A}$ grows increasingly larger as drilling continues past the point at which MAP $_{M}$ equals MAP ${ }_{A}$. Figure 8 a shows the relationship between latent drilling demand curves when $k$ equals zero and Figure $8 b$ shows this relationship when $k$ is positive.

The practical significance of the foregoing analysis is that the DOE Oil and gas model tends to overstate the cumulative amount of drilling that would be forthcoming at any level of price. For this reason, we suspect that the DOE oil and gas supply model, in fact, generates "supply curves" that overestimate the amount of production that will be supplied at each price level. 

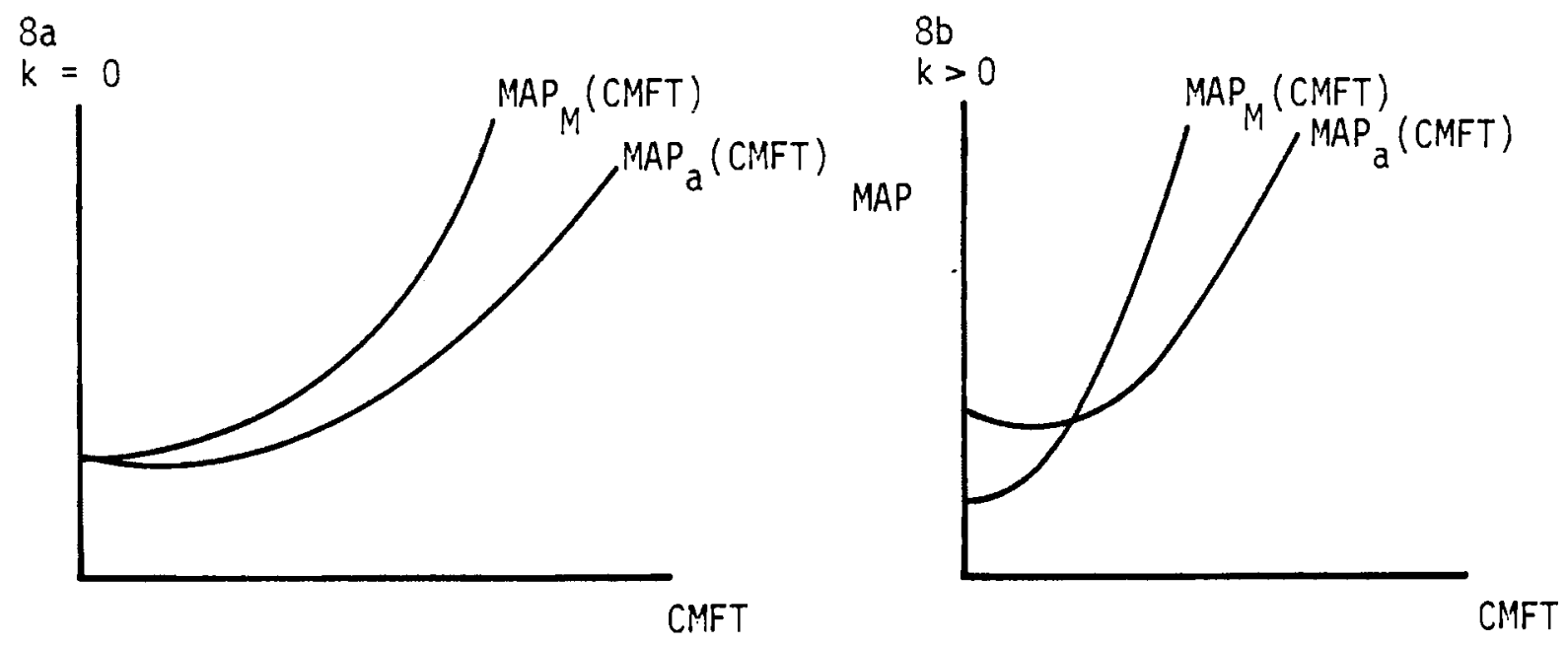

FIGURE 8. Latent Drilling Demand for Average and Marginal Resource Use Patterns

Not only wi11 projected supply from the DOE model be too high, but when "supply curves" from this model are used in the integrating model to equilibrate supply and demand for petroleum products, the equilibrium price that is calculated will be lower than that which would be expected using a supply curve based on profit maximization.

Furthermore, the analysis performed above has theoretical significance in terms of how the results of the integrating model are to be interpreted. Chapter I of The Integrating Model of the Project Independence Evaluation System; Volume IV - Model Documentation (1979) discusses how the "supply curves" generated by the oil and gas supply models are used in conjunction with demand functions to solve for equilibrium market prices. The report states that equilibrium in the fuel markets maximizes consumers' and producers' surplus. This statement is obviously incorrect since DOE "supply curves" do not accurately reflect the marginal value of resources expended in the production process. The area under DOE "supply curves", in fact, understates the value of resources expended in production, and rather than maximizing consumers' and producers' surplus, the DOE model drives discounted producers' surplus to zero (this is evident from equation 8 ). Consumers' surplus using DOE "supply curves" would be larger than it is using economic supply curves. However, 
the gain in consumers' surplus, from using a DOE "supply curve" rather than an economic supply curve, is less than the loss in producers' surplus, so that on balance, consumers' plus producers' surplus is lower than it would have been if the economic supply curve were used to calculate equilibrium price.

Figure 9 illustrates the distortion introduced in calculating consumers' and producers' surplus when a "supply curve" based on average production costs is used rather than a supply curve based on marginal production costs. The curves labeled $S_{m c}$ and $S_{a c}$ represent, respectively, an oil supply curve based on marginal cost and an oil "supply curve" based on average cost.

The downward sloping curve labeled "D" represents the demand curve for 0i1. Consumers' surplus, which measures the value of a given quantity of oil to consumers above the amount they spent to purchase that quantity, is measured by the area below the demand curve, above price. Producers' surplus, on the other hand, is measured by the area above a marginal cost supply curve $\left(S_{m c}\right)$ and below price and represents the difference between total revenue $\left(p^{\star} q_{0}\right)$ and total cost of production $\left(\int_{0}^{q} e M C d Q\right)$. The sum of producer's and consumers' surplus represents the total value to society of producing and consuming oil at a given level.

From Figure 9 it is easily seen that consumers' surplus is equal to the area $C$ ( $i j m)$ when equilibrium is achieved using a marginal cost supply curve. In this case, producers' surplus is equal to areas $A$ (fgh) and $B$ (hijg). Consumers' plus producers' surplus is equal to $A+B+C$.

When equilibrium is calculated using an average cost "supply curve," in the DOE integrating model, a new equilibrium price $\left(P_{e}{ }^{a c}\right)$ and quantity $\left(q_{e}{ }^{a c}\right)$ is established. At the new equilibrium, consumers' surplus becomes $C+B+D$ (gje). Producers' surplus becomes $A-D-E$ (ejk). Total consumers' plus producers' surplus is equal to $A+B+C-E$. Consequently, use of an average cost "supply curve" rather than an marginal cost supply results in an equilibrium solution that yields a net loss in consumers' plus producers' surplus equal to the area E. Needless to say, this equilibrium does not represent maximum consumers' plus producers' surplus. 


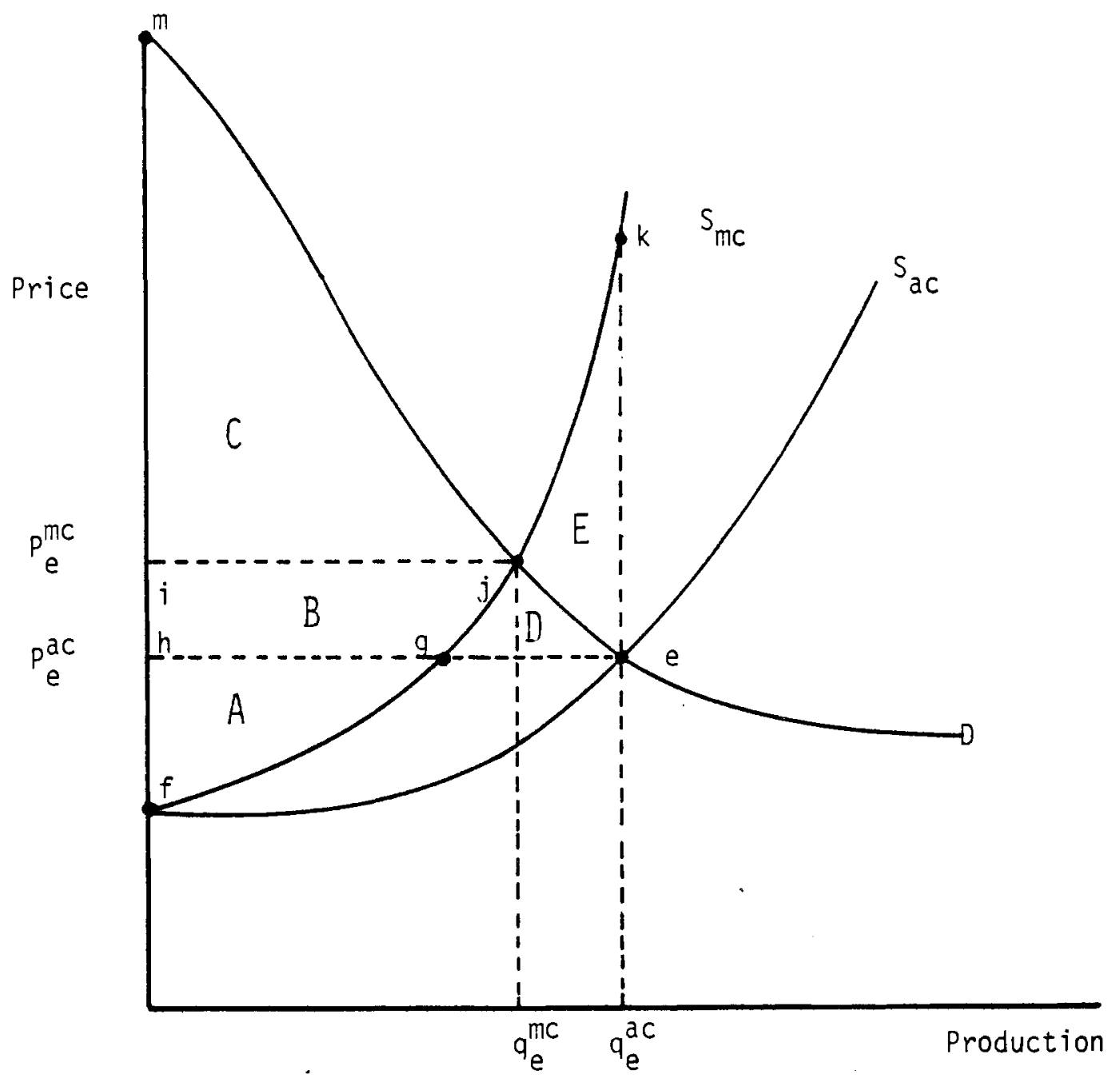

\begin{tabular}{llll} 
Supply Curve & CS & PS & Total \\
\hline$S_{m c}$ & $C$ & $A+B$ & $A+B+C$ \\
$S_{a c}$ & $C+B+D$ & $A-D-E$ & $A+B+C-E$
\end{tabular}

FIGURE 9. Consumer and Producers Surplus 
Up to this point we have concentrated our criticism of the DOE Oil and gas supply model strictly on its economic component, which is used to derive latent drilling demand curves. We have shown that the formula used to generate latent drilling demand curves tends to overstate the amount of drilling that will occur at different levels of price and, consequently, yields supply estimates that are too high, particularly at high prices. We have also shown that the use of "supply curves" by the DOE integrating model, in an equilibrium framework, estimates equilibrium values for quantities that are too high and prices that are too low. Furthermore, we have demonstrated that equilibrium solutions of the DOE integrating model possess no normative significance in terms of maximization of consumers' and producers' surplus. Thus, we have directed our criticisms to the only part of the DOE Oil and gas supply model that displays any response to economic stimuli. Our criticisms of other parts of the model are more criticisms of omission, than commission. Specifically, the DOE oil and gas supply model is weak, on economic grounds, in three areas: (1) investment in rigs and rig-building plants, (2) resource extraction rate and (3) resource valuation.

Cumulative drilling is allocated through time on the basis of rig and rig-building plant availability. The amount of rigs and plants that are available in any given time period are based wholly upon the assumption that enough plants will be added to exactly satisfy the cumulative demand for drilling. The amount of rigs produced, per plant, per year, is fixed, as well as the amount of drilling footage, per rig, per year. There is no possibility in the model for existing rigs to drill more footage in response to high price; there is no mechanism through which existing plants can increase rig production in response to heavy demand; and there is no possibility of bringing forward new plant construction to meet urgent needs. In short, there is no mechanism through which investment in rigs and rig-building plants can adjust to supply and demand conditions.

At a given level of drilling demand, capacity is added according to an inflexible schedule. When petroleum prices are projected to be high so that existing capacity is insufficient to meet demand, new capacity is added in such a way that capacity tends to build up over time. The way that the model 
is structured, capacity buildup leads to a supply curve that is shifting to the right over time, in spite of the fact that costs of production are rising as lower cost fields are depleted, leaving higher cost fields to contribute a greater proportion of total supply.

Another weakness of the DOE 011 and gas models is the use of a fixed rate of extraction. Once $0 \mathrm{il}$ and gas are added to reserves, those reserves are depleted at a rate that is invariant with respect to expected prices. While there are, no doubt, engineering factors that limit the rate of $0 i 1$ and gas extraction from reservoirs, there probably is room for some short-run variation in the rate of extraction in response to economic stimuli. There is no attempt in the DOE model to find the most profitable rate of resource extraction given expected prices and costs of production. Once again, as in the case of rig capacity, we find that the DOE model allocates supply through time in a completely rigid manner, without regard for economic incentives.

One final source of weakness in the DOE model is that it cannot differentiate between short-run and long-run resource valuation. The "supply curves" generated by the DOE oil and gas supply models represent a sort of long-run supply response to price. Each of the nine points on a "supply curve" represents the amount of production that would be forthcoming given each of nine assumed price trajectories. Implicit in each point on the "supply curve" is the assumption that the amount of production at that price is the maximum amount of production that could be supplied given available capacity and previously discovered reserves. Capacity available in any year, along with discovered reserves, depends upon the price trajectory that was assumed.

For example, if a low price trajectory is projected, less rig capacity is added and production is lower than it would have been if the projected price trajectory had been higher. Production associated with the low price trajectory and production associated with the high price trajectory form two points on a DOE "supply curve".

Consider what would happen if price were assumed to actually follow a low trajectory. Enough capacity would be available to produce only $x_{0}$ units of oil. Yet, when the "supply curve" is used in the integrating model, equilibrium quantity can actually be greater than $x_{0}$ implying that more capacity 
and reserves are available than could possibly exist if price had followed the low trajectory. Thus, given a low price trajectory and the level of production capacity associated with it, it would not be possible to increase annual production very much past $x_{0}$. It would not even be possible to reach the level of production, which is implied by a high price trajectory. This example indicates that the points on a DOE "supply curve" mix short-run and long-run supply assumptions to generate a "supply curve" that is not even internally consistent in terms of the behavior it implies. 
Several changes could be made in the MEFS oil and gas supply models to improve their performance.

- Latent drilling demand curves could be generated using a minimum acceptable price based on discounted marginal production costs $\left(\operatorname{MAP}_{A}\right)$, rather than one based on discounted average production costs $\left(\operatorname{MAP}_{A}\right)$. To accomplish this a formula such as Equation (29) could easily be substituted for that in Equation (33).

- The MEFS oil and gas models should include an investment model for rigs and rig-building plants that is reponsive to market prices, interest rates and other economic variables. This investment model should include appropriate lags between the time at which new rig capacity is called for and the time it comes on line. Both investment response and lag structure should be estimated from historical data for the petroleum industry.

- Reserves should be classified according to size, depth, pressure and location, all of which have a significant impact on production costs. This classification would require that the models be respecified to include the probability of discovering new reserves of a given size, depth, and pressure in a particular region. If the models specified that oil and gas would be extracted from reserves only if revenues exceed average variable costs of extraction, they could estimate the short-run response of production from reserves to changes in the prices of petroleum products. 


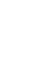




\section{DISTRIBUTION}

No. of

Copies

OFFSITE
A. A. Churm
DOE Patent Division
9800 S. Cass Avenue
Argonne, IL 60439

27 DOE Technical Information Center

John Cable

Buildings Community Systems

Department of Energy

Mail Stop $1 \mathrm{HO37}$

Forrestal Building

1000 Independence Avenue, S.W.

Washington, DC 20585

John Millhone

Buildings Community Systems

Department of Energy

Mail Stop 1 HO37

Forrestal Building

1000 Independence Avenue, S.W.

Washington, DC 20585

Peter Back

Buildings Community Systems

Department of Energy

Mail Stop 1 HO37

Forrestal Building

1000 Independence Avenue, S.W.

Washington, DC 20585

James Tanck

Buildings Community Systems

Department of Energy

Mail Stop $1 \mathrm{HO} 37$

Forrestal Building

1000 Independence Avenue, S.W. Washington, DC 20585
No. of

Copies

Jack Vitullo

Buildings Community Systems

Department of Energy

Mail Stop $1 \mathrm{H037}$

Forrestal Building

1000 Independence Avenue, S.W.

Washington, DC 20585

Charles Allen

Energy Information Administration

Department of Energy

Mail Stop 4530

Federal Building

12 th \& Pennsylvania

Washington, DC 20461

Lillian Regelson

Energy Information Administration

Department of Energy

Mail Stop 4530

Federal Building

12 th \& Pennsylvania

Washington, DC 20461

Robert Eynon

Director, Coal and Electric Power Division

Energy Information Administration

Department of Energy

Mail Stop 4530

Federal Building

12th \& Pennsylvania

Washington, DC 20461

Gene Clark

Director, Nuclear Analysis

Energy Information Administration

Department of Energy

Mail Stop 4530

Federal Building

12th \& Pennsylvania

Washington, DC 20461 
John Pearson

Director, Energy Source Analys is

Energy Information Administration

Department of Energy

Mail Stop 4530

Federal Building

12 th \& Pennsylvania

Washington, DC 20461

Julie Zalkind

Director, Mid-Term Analysis Division

Energy Information Administration

Department of Energy

Mail Stop 4530

Federal Building

12th \& Pennsylvania

Washington, DC 20461

Richard O'Neal

Director, $0 i 1$ and Gas Division

Energy Information Administration

Department of Energy

Mail Stop 4530

Federal Building

12th \& Pennsylvania

Washington, DC 20461

Richard Farmer

$0 i 1$ and Gas Division

Energy Information Administration

Department of Energy

Mail Stop 4530

Federal Building

12th \& Pennsylvania

Washington, DC 20461

Rick Thrasher

$0 i 1$ and Gas Division

Energy Information Administration

Department of Energy

Mail Stop 4530

Federal Building

12th \& Pennsylvania

Washington, DC 20461
Howard Perry

Energy Regulatory Administration

Department of Energy

Mail Stop 4002

2000 M Street

Washington, DC 20461

Neal Strauss

Office of General Counsel

Mail Stop 6 A152

Forrestal Building

1000 Independence Avenue, S.W.

Washington, DC 20585

Richard Kessler

Office of General Counsel

Mail Stop 6 A152

Forresta1 Building

1000 Independence Avenue, S.W.

Washington, DC 20585

Gurmuk Gi11

Policy Planning and Evaluation

Department of Energy

Conservation and Solar

Mail Stop 6B026

Forrestal Building

1000 Independence Avenue, S.W.

Washington, DC 20585

William Lin

Policy Planning and Evaluation

Department of Energy

Conservation and Solar

Mail Stop 6B026

Forrestal Building

1000 Independence Avenue, S.W.

Washington, DC 20585

Harvey Majors

Policy Planning and Evaluation

Department of Energy

Conservation and Solar

Mail Stop 6B026

Forrestal Building

1000 Independence Avenue, S.W. Washington, DC 20585 
No. of

Copies

V. J. Mathur

Department of Economics

1715 University Tower

Cleveland State University

Cleveland, $\mathrm{OH} 44115$

Norman Thompson

Policy and Evaluation

Department of Energy

Mail Stop 7E088

Federal Building

12th \& Pennsylvania

Washington, DC 20461

David Montgomery

Policy and Evaluation

Department of Energy

Mail Stop 7E088

Federal Building

12th \& Pennsylvania

Washington, DC 20461

William Epstein

Policy and Evaluation

Department of Energy

Mail Stop 7E088

Federal Building

12th \& Pennsylvania

Washington, DC 20461
John Corbe 11

Policy and Evaluation

Department of Energy

Mail Stop 7E088

Federal Building

12th \& Pennsylvania

Washington, DC 20461

ONSITE

DOE Richland Operations Office

H. E. Ransom

23 Pacific Northwest Laboratory

J. M. Callaway

J. W. Currie

T. J. Foley

L. A. Nieves

W. P. Patton (10)

A. D. Rockwood

J. J. Tawil

Publishing Coordination (2)

Technical Information KE (5) 
